\title{
Hip External Rotator Strength and Compensatory Movement in Three Different Positions
}

\author{
Sun-Hee Ahn', Ui-Jae Hwang1, Sung-Hoon Jung', Hyun-A Kim¹, Jun-Hee Kim¹, Oh-Yun Kwon"2,3* \\ ${ }^{1}$ Department of Physical Therapy, The Graduate School, Yonsei University, Seoul, The Republic of Korea \\ ${ }^{2}$ Department of Physical Therapy, College of Health Science, Yonsei University, Seoul, The Republic of Korea \\ ${ }^{3}$ Laboratory of Kinetic Ergocise Based on Movement Analysis, Yonsei University, Seoul, The Republic of Korea \\ Email: *kwonoy@yonsei.ac.kr
}

How to cite this paper: Ahn, S.-H., Hwang, U.-J., Jung, S.-H., Kim, H.-A, Kim, J.-H. and Kwon, O.-Y. (2018) Hip External Rotator Strength and Compensatory Movement in Three Different Positions. Health, $10,132-144$.

https://doi.org/10.4236/health.2018.101011

Received: December 27, 2017

Accepted: January 27, 2018

Published: January 30, 2018

Copyright (C) 2018 by authors and Scientific Research Publishing Inc. This work is licensed under the Creative Commons Attribution International License (CC BY 4.0).

http://creativecommons.org/licenses/by/4.0/

\begin{abstract}
Measuring intrinsic hip external rotator strength (ER) without compensatory pelvic motion and activation of the sartorius is important for preventing or rehabilitating lower extremity injuries. However, the optimal method for measuring intrinsic hip ER muscle strength while minimizing compensatory pelvic motions and activation of the sartorius is unclear. The purpose of this study is to compare measurements of hip ER strength, compensatory pelvic motion, and sartorius activation in the sitting, prone, and sidelying positions. Thirty-one healthy subjects ( 16 males and 15 females) were recruited for this study. Hip ER strength, pelvic kinematics, and sartorius muscle activation were measured during maximal isometric contraction of the hip ER in the sitting, prone, and sidelying positions. Hip ER strength was measured using a load-cell-type strength-measurement sensor. Pelvic kinematics was measured using an electromagnetic motion-tracking sensor. Electromyography was used to measure sartorius muscle activity. Data were analyzed using one-way repeated-measures analysis of variance. The result showed that hip ER strength and sartorius muscle activation were significantly lower in the sidelying compared with the sitting and prone positions $(\mathrm{p}<0.01)$. Pelvic anteroposterior tilting was significantly greater in the sitting compared with the prone and sidelying positions $(\mathrm{p}<0.01)$. Pelvic rotation differed significantly among positions $(\mathrm{p}<0.01)$. Pelvic lateral tilting was significantly greater in the prone compared with the sitting position $(\mathrm{p}<0.017)$. Compensatory pelvic motion and sartorius muscle activation were lower when hip ER strength measurements were made in the sidelying position. Therefore, the sidelying position is effective for measuring selective intrinsic hip ER strength.
\end{abstract}




\section{Keywords}

Compensatory Pelvic Motion, Hip External Rotator, Measurement Position, Sartorius

\section{Introduction}

Hip external rotator (ER) strength plays an important role in a person's daily activities [1]-[6]. Hip ER weakness causes excessive internal hip rotation and foot pronation, and increases the angle of knee valgus during weight-bearing activities [4] [7] [8]. The resulting alterations in lower extremity alignment can lead to musculoskeletal disorders that include patellofemoral pain syndrome, anterior cruciate ligament injury, femoroacetabular impingement, and iliotibial band syndrome [9] [10].

Quantifying hip muscle strength, especially hip ER muscle strength, is important for preventing and rehabilitating lower extremity injuries [11]. The strength of the hip ER muscles depends on the hip joint's position in the sagittal plane [11]. However, how it differs according to hip position is still controversy. Previous studies have demonstrated that hip rotator muscle strength differs when the hip position is altered [9] [11]. Bloom and Cornbleet (2014) reported that hip ER strength had no significant difference between sitting and supine position [11]. However, Hoglund et al. reported that hip ER strength was significantly greater in sitting compared to prone [9]. They explained this result by length-tension relationship. When the hip is extended, the ER muscles are shorter than sitting position, making it more difficult to generate force [9].

Selective measurements of primary hip ER muscle strength while excluding activation of synergistic muscles that include the sartorius are important for clinical assessment of lower extremity musculoskeletal disorders. Muscle imbalance such as weakness of primarily hip ER muscles and excessive activation of synergist muscles can increase internal hip joint forces to transverse and sagittal direction and this can lead hip joint disorders [12]. In addition, since sartorius is attached to anterior superior iliac spine (ASIS), excessive activation of sartorius causes movement of the pelvis during hip ER. If the position of the pelvis changes while testing hip ER muscle strength, the hip ER muscle lengths can change because the intrinsic hip ER muscles are attached to sacrum [13]. Alterations in muscle length may also change muscle strength because of the lengthtension relationship [9]. Therefore, control of pelvic motion and sartorius activation are important when measuring hip ER muscle strength.

The subject's position can also influence the results of hip ER strength measurements. In most previous studies, hip ER strength tests were performed with subjects in the sitting or prone position [9] [14] [15]. Measuring hip ER strength in the sitting position can activate the sartorius because this muscle acts as a hip flexor, ER, and knee flexor [13]. Performing hip ER tests in the prone position 
can cause excessive lumbopelvic rotation because subjects with lumbopelvic instability have difficulty separating lower extremity from lumbopelvic movements [16]. Determination of hip ER strength in the sidelying position may lead the pelvis be stabilized to minimize any compensatory movements and activation of the sartorius must be prevented to allow the strength of the intrinsic hip ER muscles to be selectively measured. As a result of these requirements, we designed a new method for testing hip ER strength in the sidelying position.

It is important for a variety of clinical applications to be able to measure intrinsic hip ER muscle strength while minimizing compensatory movement of the pelvis and activation of the sartorius. However, agreement regarding the best method for making these measurements has not been achieved. The purpose of this study was to compare hip ER muscle strength measurements, compensatory pelvic motion, and sartorius activation in the sitting, prone, and sidelying positions. We hypothesized that hip ER muscle strength measurements would be significantly lower in the sidelying position, and compensatory pelvic motion and sartorius activation would be significantly lower in the sidelying position.

\section{Methods}

\subsection{Subjects}

We used the $\mathrm{G}^{*}$ power program to determine the sample size using the pilot data. The sample size was calculated with a power of 0.80 , alpha level of 0.05 and effect size of 2.69. This result suggested that more than six subjects were required. Also, in previous study that compared the hip rotator muscle strength between different positions, 34 subjects were selected. Based on these results, thirty one healthy subjects (16 males and 15 females) who volunteer to this study were recruited from Yonsei University for this study [11]. Subject inclusion criteria included no historical or current back problems or lower extremity pathologies. The general characteristics of the subjects are listed in Table 1 . The study procedures were explained prior to testing, and each subject provided informed consent. The study was approved by the Yonsei University Wonju Institutional Review Board.

\subsection{Procedures}

\subsubsection{Experimental Equipment}

\section{1) Strength Measurements}

Hip ER muscle strength was measured using a Smart KEMA strength sensor

Table 1. Characteristics of the subjects $(\mathrm{N}=31)^{\star}$.

\begin{tabular}{ccc}
\hline Variables & Male $(\mathrm{n}=16)$ & Female $(\mathrm{n}=15)$ \\
\hline Age (year) & $21.7 \pm 1.7$ & $21.9 \pm 1.7$ \\
Height $(\mathrm{cm})$ & $174.1 \pm 3.7$ & $163.1 \pm 4.8$ \\
Weight $(\mathrm{kg})$ & $70.7 \pm 8.3$ & $58.9 \pm 6.9$ \\
\hline
\end{tabular}

*Values are mean \pm SD. 
(Factorial Holdings, Seoul, Korea). The two ends of the sensor were attached to the distal end of the lower leg by a strap and to a fixed bar using an adjustable belt. The belt length was adjusted for the strength test with the subject in $0^{\circ}$ hip rotation (Figure 1). The tension guage was $2 \mathrm{~kg}$ in starting position for control the tension of the belt in each test position.

Intra- and inter-rater reliability for the hip ER strength tests in all three positions was assessed in a subgroup of 10 participants ( 5 males and 5 females) using the Smart KEMA measurement system. Hip ER strength was measured twice by the same examiner to assess intra-rater test reliability, and twice by two different examiners to assess inter-rater test reliability. Hip ER muscle strength testing in all three positions showed excellent intra- $\left(\mathrm{ICC}_{3,1}>0.95\right)$ and inter-rater $\left(\mathrm{ICC}_{2,1}>0.95\right)$ test reliability.

\section{2) Electromyography}

Sartorius muscle activity was monitored using surface electromyography (EMG) while hip ER strength was being measured. Prior to the attachment of electrodes, the skin was shaved and cleaned with alcohol. Bipolar $\mathrm{Ag} / \mathrm{AgCl}$ disposable electrodes were placed parallel to the muscle fibers, $4 \mathrm{~cm}$ distal from the ASIS, and obliquely on the anterior surface of the thigh [17]. The Desktop DTS system (Noraxon, Inc., Scottsdale, AZ, USA) was used to collect EMG data, and these were subsequently processed using Myo research-XP Master Edition software (ver. 1.08; Noraxon, Inc.). Data were collected at a sampling frequency of $1,000 \mathrm{~Hz}$. Raw data were band-pass filtered at $10-500 \mathrm{~Hz}$, and root mean square (RMS) values were calculated using a moving window of $150 \mathrm{~ms}$.

\section{3) Three-Dimensional Kinematic Measurements}

Pelvic movements were monitored using a Polhemus Liberty electromagnetic motion-tracking system (Polhemus Corp., Colchester, VT, USA) while hip ER strength was being measured. The Polhemus Liberty transmitter was placed on a

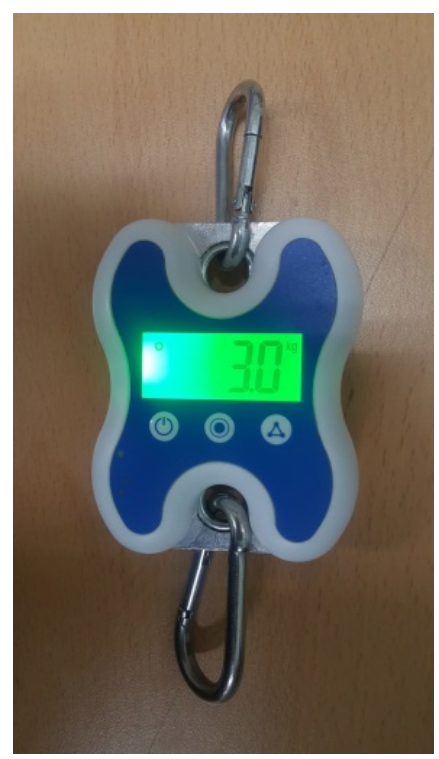

Figure 1. Load-cell type strength-measurement sensor. 
flat table near the subject to establish the global coordinates, and the sensor was attached to the sacrum by double-sided tape. The cord of sensor was also controlled by attaching according to back of subjects by tape for prevent moving artifact. A Motion Monitor data acquisition system (Innovative Sports Training, Inc., Chicago, IL, USA) was used to collect kinematic data at a sampling rate of $120 \mathrm{~Hz}$.

\subsubsection{Process}

All subjects performed maximal isometric contractions of the hip ER muscles on their dominant side for 5 seconds in the sitting, prone, and sidelying positions. This was repeated three times in each position with a 15 seconds rest between tests. The three positions were tested in random order as determined by internet based application (http://www.randomization.com); a 5 minutes rest period was provided between position changes to ensure that the muscles did not become fatigued [18].

The three positions are described below:

1) Sitting Test Position

Subjects sat at the edge of a table with their hips and knees flexed at $90^{\circ}$ and their trunk in an upright position. Knee flexion was set to $90^{\circ}$ by smartphone inclinometer application. And this was monitored during isometric strength measurement. Both feet were off the floor, and both hands were at the subject's side to stabilize the trunk (Figure 2) [13].

2) Prone Test Position

Subjects lay prone on a Styrofoam mat placed on a table. There was a hole in the center of the mat to prevent noise from the EMG sensor. Subjects then flexed the knee on the side being tested to a vertical position. $90^{\circ}$ knee angle was controlled by smartphone inclinometer application during isometric strength measurement (Figure 3) [9].

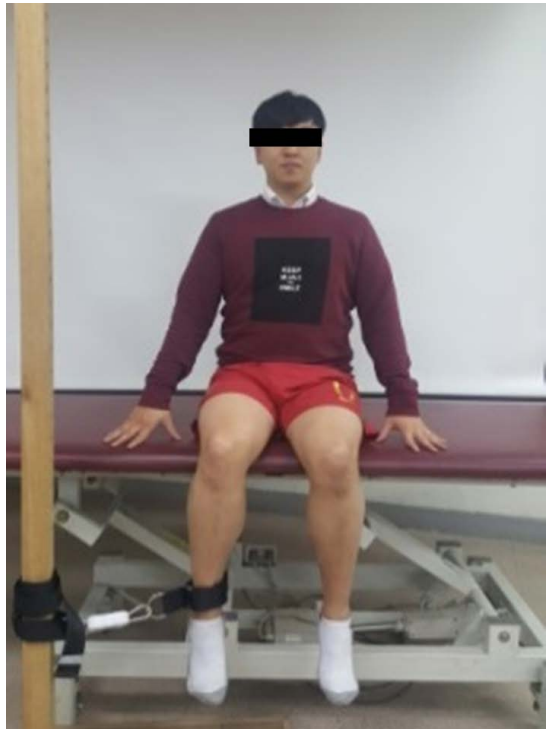

Figure 2. Sitting test position. 


\section{3) Sidelying Test Position}

Subjects lay on a table on their dominant lower extremity side. The hip joint of the leg being tested was extended to $0^{\circ}$, and the knee joint was flexed at $90^{\circ}$. Knee angle was set to $90^{\circ}$ monitored by standard goniometer during testing. The non-dominant leg was flexed, and the heel was placed anterior to the distal end of the thigh to prevent the hip from flexing. Towels were placed under the non-dominant knee to keep the pelvis in a neutral starting position (Figure 4).

\subsubsection{Data Analysis}

\section{1) Hip ER Strength}

Hip ER strength was measured using a tensiometer in the sitting, prone, and sidelying positions. Subjects were asked to externally rotate the dominant leg as far as possible for $5 \mathrm{~s}$. The strength data of middle $3 \mathrm{~s}$ of $5 \mathrm{~s}$ of isometric contraction of the ER muscles were averaged and normalized to the subject's weight.

\section{2) Sartorius Muscle Activity}

Sartorius EMG data were collected over the $5 \mathrm{~s}$ of the hip ER strength test in the sitting, prone, and sidelying positions. The middle $3 \mathrm{~s}$ of the $5 \mathrm{~s}$ of EMG data were processed. RMS values were normalized to maximal voluntary isometric contraction (MVIC). For MVIC measurements, resistance was applied to oppose hip flexing, external rotation, abduction, and knee flexing in the supine position

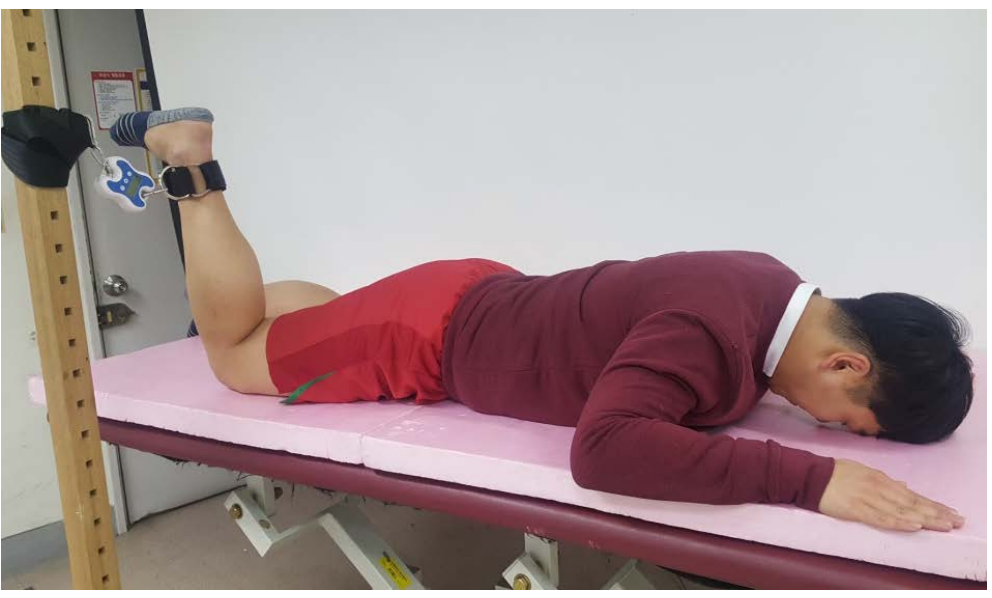

Figure 3. Prone test position.

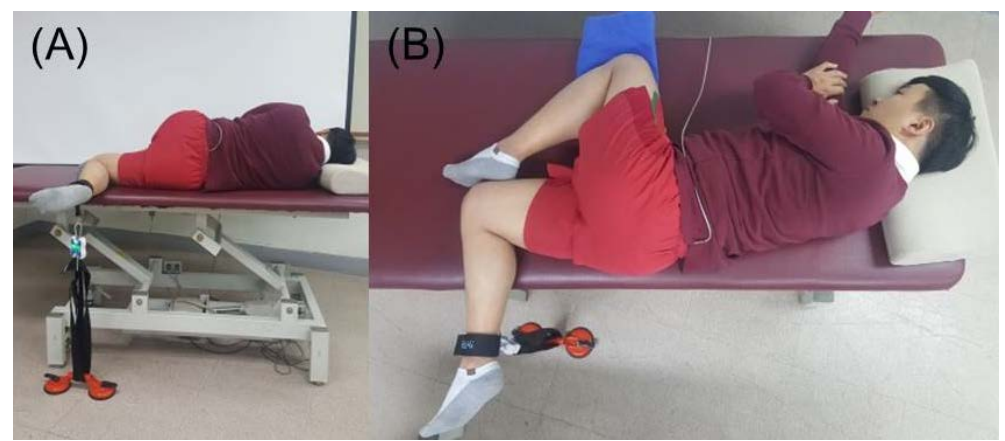

Figure 4. Sidelying test position: (A) posterior view and (B) sagittal view. 
as recommended by Hislop and Mongomery [13]. Average MVIC data from three trials were used to calculate $100 \%$ MVIC.

\section{3) Pelvic Kinematics}

To record pelvic kinematic data while hip ER strength was being measured, a sensor was attached to the sacrum. Movement of the sensor in three directions was monitored by a transmitter to indicate pelvic anteroposterior (A-P) tilting, lateral tilting, and rotation. The kinematic data were collected for $5 \mathrm{~s}$ in the starting position and for $5 \mathrm{~s}$ while the hip ER strength measurements were being made. Collected data from $3 \mathrm{~s}$ to $4 \mathrm{~s}$ during $5 \mathrm{~s}$ isometric contractions and starting position were averaged and difference value between starting position and testing position was used for data analysis. Differences in kinematic data values between the starting and strength measurement positions indicated movement of the pelvis.

\subsection{Statistical Analysis}

Statistical analysis was performed using SPSS for windows software (ver. 23.0; SPSS, Inc., Chicago, IL, USA). The Kolmogorov-Smirnov test was used to confirm that the data were normally distributed. One-way repeated-measures analysis of variance (ANOVA) was used to compare hip ER strength, sartorius muscle activity, and pelvic motion in the three positions. The level of significance was set at $\alpha=0.05$. Fisher's least-significant-difference test was used for post hoc analyses $(\alpha=0.05 / 3=0.017)$.

\section{Results}

\subsection{Hip ER Strength}

Hip ER strength normalized to body weight differed significantly among the three positions $(\mathrm{p}<0.01)$. The post hoc tests demonstrated that hip ER muscle strength was significantly lower in the sidelying compared with the sitting and prone positions (sitting vs. sidelying mean difference: $0.008,95 \%$ confidence interval $[\mathrm{CI}]: 0.03,-0.07, \mathrm{p}<0.01$; prone vs. sidelying mean difference: $0.009,95 \%$ CI: $0.02,-0.06, \mathrm{p}<0.01$ ) (Figure 5).

\subsection{Sartorius Muscle Activity}

Sartorius muscle activity differed significantly among the three positions ( $\mathrm{p}<$ 0.01 ). The post hoc tests demonstrated that sartorius muscle activity was significantly lower in the sidelying compared with the sitting and prone positions (sitting vs. side lying mean difference: $3.17,95 \% \mathrm{CI}: 4.61,-17.55, \mathrm{p}=0.001$; prone vs. sidelying mean difference: $2.45,95 \% \mathrm{CI}: 2.51,-12.52, \mathrm{p}=0.005)$ (Figure 6).

\subsection{Pelvic Kinematics}

Pelvic A-P tilting, rotation, and lateral tilting all differed significantly among the three positions $(\mathrm{p}<0.05)$. There was significantly more A-P tilting in the sitting compared with the prone and sidelying positions (sitting vs. prone mean 


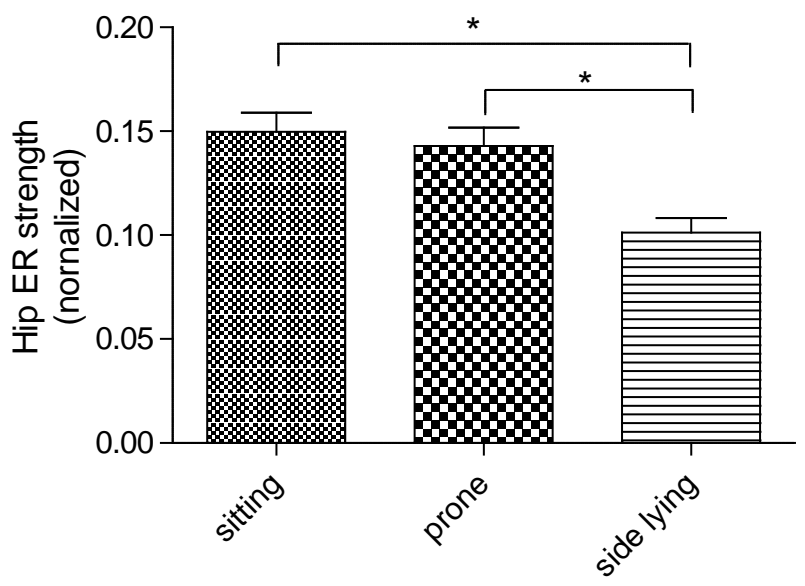

Figure 5. Hip ER muscle strength normalized to weight in the three positions (mean $\pm \mathrm{SD}) .{ }^{*}$ Significant difference $(\mathrm{p}<0.017)$.

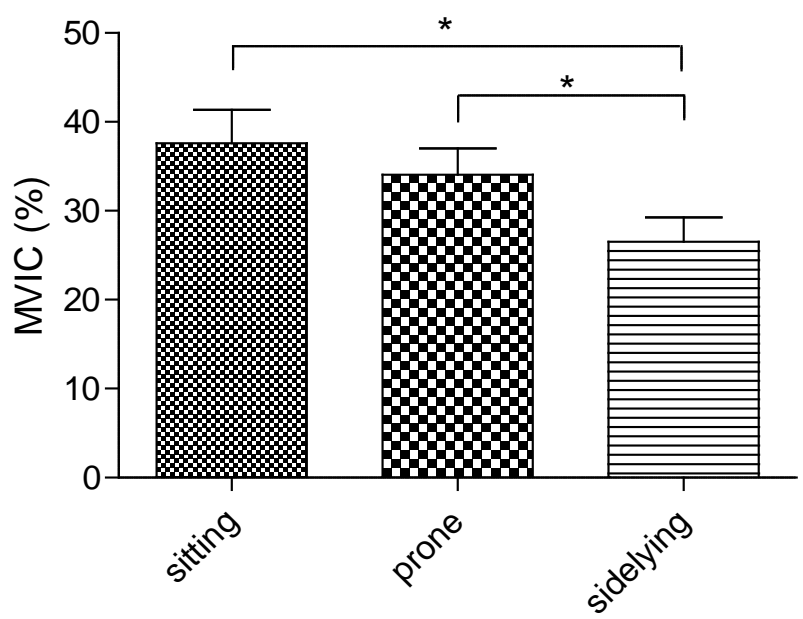

Figure 6. Sartorius muscle activity in the three positions (mean $\pm \mathrm{SD}) .{ }^{\star}$ Significant difference $(\mathrm{p}<0.017)$.

difference: $2.67,95 \%$ CI: 8.23, -19.12 , p < 0.01; sitting vs. sidelying mean difference: $2.6,95 \%$ CI: $8.06,-18.69, \mathrm{p}<0.01)$. Pelvic rotation was significantly greater in the sitting compared with the prone and sidelying positions, and also significantly greater in the prone compared with the sidelying position (sitting vs. prone mean difference: $2.33,95 \% \mathrm{CI}: 4.05,-13.56, \mathrm{p}=0.001$; sitting vs. sidelying mean difference: $2.18,95 \% \mathrm{CI}: 7.23,-16.14$, $\mathrm{p}<0.01$; prone vs. sidelying mean difference: $0.6,95 \%$ CI: $1.65,-4.11, \mathrm{p}<0.01$ ). There was significantly more lateral pelvic tilting in the prone compared with the sitting position (sitting vs. prone mean difference: $0.65,95 \% \mathrm{CI}:-3.07,-0.4, \mathrm{p}=0.012$ ) (Figure 7 ).

\section{Discussion}

The purpose of this study was to compare hip ER strength, compensatory pelvic motion, and sartorius activation in the sitting, prone, and sidelying positions. To our knowledge, our study is the first to investigate hip ER strength and the compensatory movements that occur when ER strength is measured. As we 


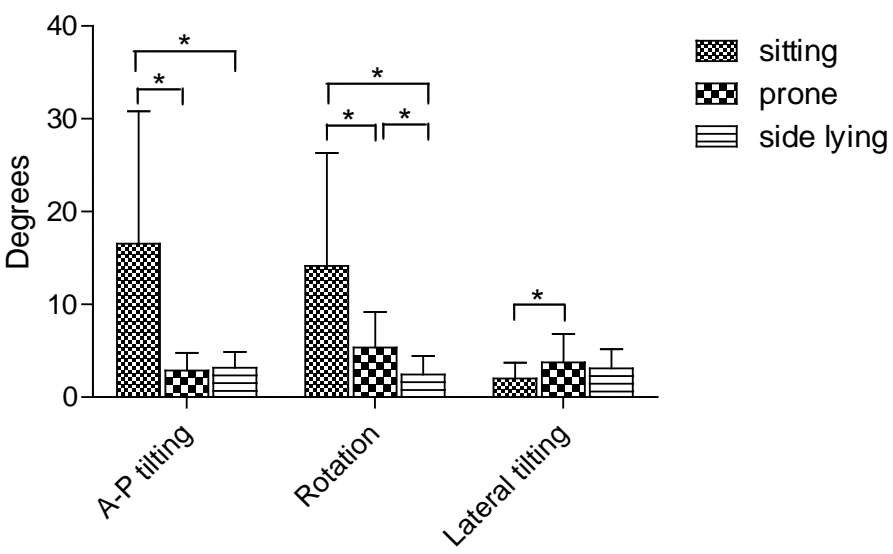

Figure 7. Pelvic kinematics in the three positions (mean $\pm S D$ ). ${ }^{*}$ significant difference $(\mathrm{p}<0.017)$.

hypothesized, the results of our study demonstrated that hip ER strength was significantly lower in the sidelying compared with the sitting and prone positions. In addition, compensatory pelvic A-P tilting and rotation, and sartorius muscle activation were significantly lower in the sidelying position.

Several previous studies investigated the effect of joint position on hip ER strength, but the results were inconsistent [9] [11] [18]. Bloom and Cornbleet's (2014) HHD measurements demonstrated no difference in hip ER strength measured in the supine or sitting positions (supine position: $29 \mathrm{lb}$, sitting position: $30.5 \mathrm{lb}$ ) [11]. Conversely, Lindsay et al. (1992) investigated isokinetic hip ER strength using a Cybex isokinetic dynamometer and demonstrated that hip ER torque per body-weight percentage was significantly higher in the sitting compared with the supine position (supine position with knees flexed: $20.1 \%$; supine position with knees extended: $43.6 \%$; sitting position: $50.8 \%$; male $\mathrm{F}=$ 689.7; female $\mathrm{F}=609.8$ ) [18]. Hoglund et al. (2014) also demonstrated that hip ER muscle strength normalized to body weight was significantly greater in the sitting compared with the prone position (sitting position: 0.2 ; prone position: 0.18) [9]. They explained the greater hip ER strength in the sitting position using the length-tension relationship. The results of our study were similar to those of Lindsay et al. (1992) and also Hoglund et al. (2014) Hip ER strength normalized to body weight was greatest in the sitting position (sitting: 0.15 ; prone: 0.14 ; side lying: 0.10) [9] [18]. However, the significantly greater hip ER strength in the prone compared with the sidelying position cannot be explained by the length-tension relationship because the hip ER muscle length was the same in both positions. Therefore, to explain this result, we need to identify other factors that differentially affect strength in the prone and sidelying positions. One plausible explanation is the effect of gravity. Humans perform physical activities in the presence of gravity, and therefore muscle strength is influenced by a subject's weight. Consequently, manual muscle testing as defined by Lowman et al. takes the effect of gravity into account [19] [20]. In the prone position, external rotation of the hip is assisted by gravity. However, in the sidelying position, hip ex- 
ternal rotation for strength measurements occurs against the force of gravity. Therefore, the weight of the limb may have influenced the result, indicating greater hip ER strength in the prone position. Other factors that might have had differential effects on hip ER strength measurements include activation of the sartorius and the pelvic kinematics that were measured in the present study.

Sartorius muscle activity was significantly lower in the sidelying compared with the sitting and prone positions. The sartorius muscle acts as a hip flexor, abductor, ER, and knee flexor [13]. In sitting position, sartorius is likely to act in the direction of hip ER because hip is flexed. The prone and sidelying position are the position which the hip is extended to inhibit the action of sartorius. However, in prone position, movement of pelvic occurs to anterior tilting and rotation on the fixed knee joint during hip ER isometric contraction. This causes the movement of ASIS, which is the proximal attachment of sartorius, to activate the sartorius well. In sidelying position, pelvic movement was the smallest among three positions. Thus, it was able to maintain the hip extended position during hip ER isometric contraction, and sartorius muscle had well inhibited.

Compensatory pelvic movements differed significantly among the three positions. In the sitting position, the pelvis was rotated and markedly tilted toward the A-P side compared with the prone and sidelying positions. Although pelvic rotation and A-P tilting were lower in the prone compared with the sitting position, pelvic rotation was still greater than in the sidelying position, and pelvic lateral tilting was greater than in the sitting position. Sartorius muscle activation was greatest in the sitting position. The sartorius is an extrinsic muscle that is attached to the ASIS and the medial condyle of the femur [13]. Therefore, activation of the sartorius in the sitting position can lead to A-P tilting and rotation of the pelvis. In the prone position, the pelvis apparently rotated when the sartorius contracted to adopt its optimal length for generating force. This study demonstrated that the typical positions used to measure hip ER strength, which include the sitting and prone positions can lead to excessive movement of the pelvis when making these measurements. Excessive pelvic motion can cause lumbar spine instability, which may lead to back pain. In the sidelying position, pelvic tilting and rotation were prevented by adducting and flexing the other leg. Therefore, this study demonstrated that pelvic A-P tilting and rotation are minimal in the sidelying position.

To rehabilitate lower extremity conditions, it is important that intrinsic hip ER strength be measured selectively. However, hip ER strength measurements are affected by the subject's position. Therefore, clinicians need to consider the optimal position for measuring hip ER strength. Compensatory movements and over-activation of synergistic muscle groups may interfere with selective muscle-strength tests. In this study, greater activation of the sartorius muscle and compensatory pelvic movements were observed in the sitting and prone positions, which have typically been used to measure hip ER strength. Excessive pelvic motion can generate stress in the lumbar spine. Therefore, clinicians need to 
be cautious when measuring hip ER strength or training hip ER muscles in patients with lumbopelvic instability. Testing hip ER strength in the sidelying position was designed to reduce both compensatory pelvic movements and activation of the sartorius, which is an extrinsic hip ER muscle. As hypothesized, muscular strength was significantly lower and compensatory pelvic motion and sartorius muscle activation lower in the sidelying position compared with the sitting and prone positions. This indirectly suggests that the strength of the intrinsic hip ER muscles is being selectively measured in the sidelying position. The results of this study suggest that the sidelying position should be recommended for measuring intrinsic hip ER strength, especially in patients with lumbopelvic instability.

This study has several limitations. First, we did not measure activation of the intrinsic hip ER muscles directly. Instead we defined selective measurement of intrinsic hip ER muscle strength by diminished compensatory movements and extrinsic activity of the sartorius. The intrinsic hip ER muscles are located under the gluteus maximus, which is a thick extrinsic muscle. Therefore, activation of these muscles cannot be measured using surface EMG. Fine-wire EMG should be used to measure intrinsic hip ER activity in a future study. Second, only healthy subjects participated in this study. Therefore, it is uncertain that our methods are suitable for patients with lower extremity disease. In a further study, we should investigate the effect of measuring and training hip ER muscles in the sidelying position using subjects with lower extremity musculoskeletal disease.

\section{Conclusion}

This study compared the measurement of hip ER strength, compensatory pelvic motion, and sartorius muscle activation in three positions. Hip ER strength was significantly lower in the sidelying position; compensatory pelvic A-P tilting and rotation and sartorius muscle activation were also lower in the sidelying position. Compensatory movements can prevent selective measurement of intrinsic hip ER strength. In addition, excessive movement of the pelvis while measuring hip ER strength or training hip ER muscles may aggravate back pain due to repeated movement of the lumbar spine. Therefore, clinicians should consider using the sidelying position for hip ER strength measurements and training the hip ER muscles to control compensatory pelvic motion and sartorius activation.

\section{References}

[1] Augustsson, J. (2016) A New Clinical Muscle Function Test for Assessment of Hip External Rotation Strength. International Journal of Sports Physical Therapy, 11, 520-526.

[2] Feinberg, J.H. (2000) The Relationship between Lower-Extremity Injury, Low Back Pain, and Hip Muscle Strength in Male and Female Collegiate Athletes. Clinical Journal of Sport Medicine, 10, 89-97. https://doi.org/10.1097/00042752-200004000-00002 
[3] Guralnik, J.M., Ferrucci, L., Simonsick, E.M., Salive, M.E. and Wallace, R.B. (1995) Lower-Extremity Function in Persons over the Age of 70 Years as a Predictor of Subsequent Disability. The New England Journal of Medicine, 332, 556-561. https://doi.org/10.1056/NEJM199503023320902

[4] Ireland, M.L., Willson, J.D., Ballantyne, B.T. and Davis, I.M. (2003) Hip Strength in Females with and without Patellofemoral Pain. Journal of Orthopaedic \& Sports Physical Therapy, 33, 671-676. https://doi.org/10.2519/jospt.2003.33.11.671

[5] Powers, C.M. (2003) The Influence of Altered Lower-Extremity Kinematics on Patellofemoral Joint Dysfunction: A Theoretical Perspective. Journal of Orthopaedic \& Sports Physical Therapy, 33, 639-646.

https://doi.org/10.2519/jospt.2003.33.11.639

[6] Souza, R.B. and Powers, C.M. (2009) Differences in Hip Kinematics, Muscle Strength, and Muscle Activation between Subjects with and without Patellofemoral Pain. Journal of Orthopaedic \& Sports Physical Therapy, 39, 12-19. https://doi.org/10.2519/jospt.2009.2885

[7] Lee, S.P. and Powers, C. (2013) Description of a Weight-Bearing Method to Assess Hip Abductor and External Rotator Muscle Performance. Journal of Orthopaedic \& Sports Physical Therapy, 43, 392-397. https://doi.org/10.2519/jospt.2013.4412

[8] Powers, C.M. (2010) The Influence of Abnormal Hip Mechanics on Knee Injury: A Biomechanical Perspective. Journal of Orthopaedic \& Sports Physical Therapy, 40, 42-51. https://doi.org/10.2519/jospt.2010.3337

[9] Hoglund, L.T., Wong, A.L. and Rickards, C. (2014) The Impact of Sagittal Plane Hip Position on Isometric Force of Hip External Rotator and Internal Rotator Muscles in Healthy Young Adults. International Journal of Sports Physical Therapy, 9, 58-67.

[10] Khayambashi, K., Mohammadkhani, Z., Ghaznavi, K., Lyle, M.A. and Powers, C.M. (2012) The Effects of Isolated Hip Abductor and External Rotator Muscle Strengthening on Pain, Health Status, and Hip Strength in Females with Patellofemoral Pain: A Randomized Controlled Trial. Journal of Orthopaedic \& Sports Physical Therapy, 42, 22-29. https://doi.org/10.2519/jospt.2012.3704

[11] Bloom, N. and Cornbleet, S.L. (2014) Hip Rotator Strength in Healthy Young Adults Measured in Hip Flexion and Extension by Using a Hand-Held Dynamometer. $P M R, 6,1137-1142$. https://doi.org/10.1016/j.pmrj.2014.06.002

[12] Lewis, C.L., Sahrmann, S.A. and Moran, D.W. (2009) Effect of Position and Alteration in Synergist Muscle Force Contribution on Hip Forces When Performing Hip Strengthening Exercises. Clinical Biomechanics, 24, 35-42. https://doi.org/10.1016/j.clinbiomech.2008.09.006

[13] Hislop, H. and Montgomery, J. (2007) Daniels and Worthingham's Muscle Testing: Techniques of Manual Examination. 8th Edition, WB Saunders, Birmingham, AL, 210.

[14] Gordon, A.T., Ambegaonkar, J.P. and Caswell, S.V. (2013) Relationships between Core Strength, Hip External Rotator Muscle Strength, and Star Excursion Balance Test Performance in Female Lacrosse Players. International Journal of Sports Physical Therapy, 8, 97-104.

[15] Mentiplay, B.F., Perraton, L.G., Bower, K.J., Adair, B., Pua, Y.H., Williams, G.P., McGaw, R. and Clark, R.A. (2015) Assessment of Lower Limb Muscle Strength and Power Using Hand-Held and Fixed Dynamometry: A Reliability and Validity Study. PLoS One, 10, e0140822. https://doi.org/10.1371/journal.pone.0140822

[16] Comerford, M. and Mottram, S. (2012) Kinetic Control: The Management of Un- 
controlled Movement. Elsevier, Amsterdam.

[17] Criswell, E. (2010) Cram's Introduction to Surface Electromyography. 2nd Edition, Jones \& Bartlett Publishers, Burlington, VT, 362.

[18] Lindsay, D.M., Maitland, M.E., Lowe, R.C. and Kane, T.J. (1992) Comparison of Isokinetic Internal and External Rotation Torques Using Different Testing Positions. Journal of Orthopaedic \& Sports Physical Therapy, 16, 43-50. https://doi.org/10.2519/jospt.1992.16.1.43

[19] Hislop, H., Avers, D. and Brown, M. (2013) Daniels and Worthingham's Muscle Testing: Techniques of Manual Examination: Principles of Manual Muscle Testing. Elsevier Health Sciences, Amsterdam, 203-278.

[20] Usa, H., Matsumura, M., Ichikawa, K. and Takei, H. (2017) A Maximum Muscle Strength Prediction Formula Using Theoretical Grade 3 Muscle Strength Value in Daniels et al.'s Manual Muscle Test, in Consideration of Age: An Investigation of Hip and Knee Joint Flexion and Extension. Rehabilitation Research and Practice, 2017, Article ID: 3985283. https://doi.org/10.1155/2017/3985283 